\title{
Zambia: Peer educators can promote safer sex behaviors
}

Frontiers in Reproductive Health

Follow this and additional works at: https://knowledgecommons.popcouncil.org/departments_sbsr-rh

Part of the Civic and Community Engagement Commons, Demography, Population, and Ecology Commons, International Public Health Commons, and the Public Health Education and Promotion Commons How does access to this work benefit you? Let us know!

\section{Recommended Citation}

"Zambia: Peer educators can promote safer sex behaviors," FRONTIERS OR Summary. Washington, DC: Population Council, 2001. 
Zambia

Youth Reproduc-

tive Health

OR Summary 17

\section{Peer Educators Can Promote Safer Sex Behaviors}

\begin{abstract}
Two interventions - condom distribution by peer educators and small business loans to youth aged 14-19 - led to safer sexual practices among adolescents in peri-urban communities. Both program participants and their peers reported an increase in abstinence and monogamy and a decrease in sexually transmitted infections. Youth in the intervention areas were better informed about ways to prevent HIV/AIDS than those in the control group. However, the interventions did not lead to greater use of contraception or condoms for dual protection.
\end{abstract}

\section{Background}

Zambian adolescents are at high risk of unwanted pregnancy, sexually transmitted infections (STIs), and HIV infection due to early sexual initiation, low use of contraceptives and condoms, and other highrisk sexual behaviors.

During 1996-98, CARE Zambia, with the assistance of Population Council, conducted a study to test community-based approaches to improve adolescent sexual and reproductive health. In collaboration with the Planned Parenthood Association of Zambia and the Makeni Ecumenical Center, CARE Zambia talked to adolescents in four communities outside Lusaka. Using participatory learning and action (PLA) techniques, the researchers identified many factors leading to high-risk sexual behaviors, including the lack of economic, recreational, and educational opportunities for youth.

This information helped to design the study, which was conducted in four areas for 20 months: (1) One area had condom distribution by peer educators; (2) One area had loans to adolescents aged 14-19 for small businesses, with training in business skills and information on sexual and reproductive health
(SRH); (3) Both these interventions were implemented in a third area; and (4) A fourth area served as the control site.

Pre- and post-intervention information was collected in the four study communities using PLA techniques, in-depth interviews with 35 peer educators and 47 loan recipients, surveys of 83 peer educators and 103 loan recipients, a baseline survey of 1,634 adolescents, and a post-intervention survey of 1,720 adolescents.

\section{Findings}

- The 130 adolescents trained as peer educators conducted more than 4,000 SRH counseling sessions and distributed more than 65,600 condoms, reaching between 4 and 15 percent of the adolescents in their area. Most youth who use condoms, however, obtain them from the market or shops.

- Loan recipients learned new skills and changed their outlook for the future. Of the 221 youth who received small loans averaging US\$67, half were female and none was attending school. About four in five of the 47 loan recipients interviewed said that they had accomplished something "useful" with their 
loan, including meeting family and personal needs, starting school, and buying goods for their business.

- However, the intervention did not lead to a revolving credit system, since less than one-third of the amount loaned was repaid. Some youth were pressured to pay family debts, became ill, or loaned money that was not repaid. Girls were more likely than boys to repay loans.

- Of the two interventions tested, the use of peer educators appeared to have more effect on the sexual behavior of participants than the loan scheme. Nearly all 83 peer educators and nearly half of the 103 loan recipients surveyed at the project's end reported increased abstinence and monogamy in the previous three months as well as greater knowledge of ways to prevent HIV/AIDS. Some participants reported more frequent contraceptive and condom use than before, but the findings were inconsistent.

- Both interventions led to safer sexual behaviors in the community. Changes that were found in the three intervention areas but not in the control area were: more adolescents reported they were monogamous in the previous three months (see Figure), more youth could name at least two ways to prevent the spread of HIV/AIDS, fewer youth had had an STI in the previous nine months, and more youth sought STI treatment from an STI clinic rather than a traditional healer. No difference was found in condom or contraceptive use in the previous three months or in the age or

proportion of adolescents initiating sexual activity. Combining the two interventions did not yield greater impact.
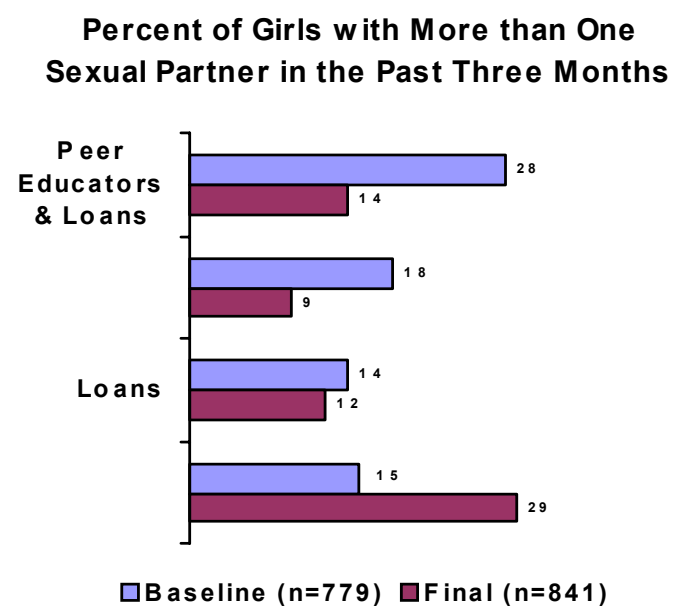

\section{Policy Implications}

- Adolescents are concerned about jobs and educational opportunities as well as reproductive health and thus need broad multi-faced programs to address their needs.

- Peer educator programs are labor-intensive, but they can lead to safer sexual behaviors among both the peer educators and the youth that they counsel.

- Loan programs benefit out-of-school youth but are difficult to sustain because of problems with loan repayment. In selecting loan recipients, programs should choose young women, youth already in business, and those willing to open a savings account. The grace period and repayment deadline should be short to encourage repayment.

- Programs need to reduce the stigma that youth associate with condoms.

Fetters, Tamara, Fines Munkonze, and Julie Solo. 1999. Investing in Youth: Testing Community Based Approaches for Improving Adolescent Sexual and Reproductive Health. CARE Zambia and Population Council.. For more information, contact: Population Council, P.O. Box 17643, Nairobi, Kenya.Tel.254-2-713-480; Fax 254-2-713-479; E-mail: publications@popcouncil.or.ke.

This project was conducted with support from the U.S. AGENCY FOR INTERNATIONAL DEVELOPMENT under Contract Number CCP3030-C-00-3008-00. 